\title{
ANÁLISE QUÍMICO-MINERALÓGICA DE OCRES E A BUSCA POR CORRELAÇÕES ARQUEOLÓGICAS COM OS PIGMENTOS DE PINTURAS RUPESTRES DO SÍTIO PEDRA DO CANTAGALO I ${ }^{1}$
}

\author{
CHEMICAL-MINERALOGICAL ANALYSIS OF OCHRES AND \\ THE SEARCH FOR ARCHAEOLOGICAL CORRELATIONS WITH \\ THE PIGMENTS OF RUPESTRIAN PAINTINGS OF THE SITE \\ PEDRA DO CANTAGALO I
}

\author{
Heralda Kelis Sousa Bezerra da Silva ${ }^{2}$ \\ dekelis.sousa@hotmail.com \\ Luis Carlos Duarte Cavalcante ${ }^{3}$ \\ cavalcanteufpi@ufpi.edu.br \\ José Domingos Fabris ${ }^{4}$ \\ jdfabris@gmail.com
}

\section{RESUMO}

Este trabalho foi devotado à análise arqueométrica de ocres vermelhos e amarelos do sítio arqueológico Pedra do Cantagalo I, Piripiri, Piauí. Prospecções foram efetuadas nas proximidades do abrigo rochoso, no interesse particular de se identificar jazidas fontes dos pigmentos minerais das pinturas rupestres. A composição químico-mineralógica dos ocres foi correlacionada com os dados correspondentes aos dos materiais minerais oriundos das jazidas do entorno e das camadas de tintas das pinturas rupestres das superfícies areníticas decoradas do sítio. Os resultados obtidos mostram evidências de que os ocres fontes dos pigmentos das pinturas rupestres foram originalmente enriquecidos, na preparação arqueológica, por concentração das espécies oxídicas ferruginosas e aluminosas, às expensas da redução quantitativa dos minerais silicatados, do material precursor diretamente retirado das jazidas.

Palavras-chave: Ocres. Espectroscopia Mössbauer. Arqueometria.

\footnotetext{
${ }^{1}$ Resumo de Dissertação de Mestrado, defendida no Programa de Pós-Graduação em Arqueologia, UFPI, orientada pelo Prof. Luis Carlos Duarte Cavalcante em 2018.

${ }^{2}$ Discente, Programa de Pós-Graduação em Arqueologia da UFPI.

${ }^{3}$ Departamento de Arqueologia, UFPI.

${ }^{4}$ Departamento de Química, UFMG.
} 


\begin{abstract}
This archaeometric work was devoted to the chemical-mineralogical characterization of red and yellow ochres of the archaeological site Pedra do Cantagalo I, Piripiri, Piauí. Field surveys were made in the neighboring of the rocky shelter, seeking for any apparent evidence signalizing the mineral source of such mineral pigments. The chemicalmineralogical composition of the ochres was correlated with corresponding data obtained from analyzing the nature of the minerals from the surrounding deposits and from the paint layers of the rupestrian paintings on the decorated sandstone surfaces of this archaeological site. The results for the ochres fairly show clear evidence that the ferruginous phases, as well as aluminum-containing minerals, were prepared for the enrichment in iron oxides, apparently at the expense of the removal of silicate minerals, from the material withdrawn from the deposits.
\end{abstract}

Keywords: Ochres. Mössbauer spectroscopy. Archaeometry.

\title{
CONTEXTO DA PESQUISA
}

O que se sabe sobre o homem pré-histórico está relatado nos livros clássicos e em artigos científicos que, revelam uma história contada com base nos vestígios deixados por grupos humanos antigos, conforme tais fragmentos testemunhais têm sido, aos poucos, evidenciados. Pode-se depreender, desses vestígios, que o homem pré-histórico soube aproveitar com destreza e harmonia os recursos naturais disponíveis, pois os artefatos encontrados em prospecção e em escavações arqueológicas, como por exemplo urnas funerárias, machados ou picoteadores feitos de pedra, e inúmeros outros tipos de instrumentos, mostram que ele se utilizava das matérias-primas disponíveis no seu ambiente de entorno e que fazia escolhas, quando se tratava de fabricar algo de que necessitava para sua sobrevivência, para a prática de rituais ou até mesmo como passatempo. Felizmente, à medida que os arqueólogos vão descobrindo esses vestígios, deixados intencionalmente ou não pelos grupos humanos pré-históricos, abrem-se 
possibilidades para se estudar e aprender um pouco mais sobre a vida cotidiana dos homens pretéritos.

Os registros rupestres pintados e/ou gravados são vestígios enigmáticos, pois não se sabe o porquê de terem sido deixados nas paredes e nos tetos de abrigos sobrocha ou cavernas, em blocos rochosos isolados ou em lajedos a céu aberto, em vários tipos de suportes (arenito, granito, calcário, etc.), expostos às intempéries naturais. Alguns sítios que contêm tais registros pictóricos os exibem em uma variedade de cores. Contudo, a cor vermelha é a mais frequente. Embora sejam raros, também ocorrem casos em que gravuras rupestres são pintadas.

A tinta é uma mistura de várias substâncias, entre as quais se destacam os componentes responsáveis pela cor. O homem pré-histórico, como ser pensante que é (DESCARTES, 2001), também teve a ideia de misturar algumas "substâncias" encontradas na natureza, para obter a coloração pretendida, preparar a própria tinta e realizar suas atividades de pinturas nas rochas. Os materiais pictóricos primários, usados em misturas pelos grupos humanos pré-históricos para obter tinta, suscitam no pesquisador alguns questionamentos, notadamente sobre os componentes da tinta natural que eles utilizaram, pois antes de as indústrias criarem as tintas atuais, várias formulações tiveram que ser testadas nos laboratórios modernos, embora a maioria delas ainda seja obtida dos mesmos minerais encontrados na natureza. 
Da ampla gama de trabalhos científicos disponíveis na literatura sobre a investigação de tintas pré-históricas, a maioria está voltada para a análise arqueométrica, mais pontualmente químico-mineralógica, dos pigmentos.

A arqueometria foi uma estratégia interdisciplinar a que se recorreu, neste trabalho, para se alcançarem os dados à construção de um modelo suficientemente consistente e seguro sobre as matérias-primas utilizadas na elaboração das tintas e sobre os procedimentos utilizados na sua preparação. Como os químicos atuais, o homem pré-histórico possivelmente realizou testes nos materiais que encontrava na natureza, até chegar à cor desejada. É notório que a cor fazia parte do seu cotidiano, pois a existência de sítios de arte rupestre, seja com predominância de tonalidades avermelhadas, ou dessas em associação com outras cores, é disso uma evidência.

O objetivo geral deste trabalho foi realizar a caracterização químico-mineralógica dos ocres do sítio Pedra do Cantagalo I (localizado no município de Piripiri, Piauí) e dos pigmentos minerais de jazidas do entorno, visando estabelecer correlações com a composição correspondente dos pigmentos das pinturas rupestres existentes nas paredes, reentrâncias e saliências desse abrigo pré-colonial. Pretendeu-se, portanto, verificar se o material pictórico encontrado em superfície, em estratigrafia (nas sondagens) e, eventualmente, em jazidas do entorno, era idêntico ao utilizado na confecção da arte rupestre. 
Para se atingir o objetivo proposto, buscou-se: (i) determinar a composição química elementar dos ocres e dos pigmentos minerais, para conhecer os elementos químicos que os constituem e em que proporção aparecem nos materiais; (ii) identificar as fases minerais constituintes dos ocres e dos pigmentos minerais do entorno, pois, dependendo do modo de preparação dos pigmentos, podem ter ocorrido transformações de fase; (iii) investigar a existência de espécies magnéticas entre os constituintes dos vestígios em foco e verificar a possibilidade de utilizá-las como indicadores de identificação de origem do material, ou como indicadores de padrão tecnológico utilizado na preparação dos pigmentos; (iv) comparar os pigmentos minerais coletados na superfície e em estratigrafia do sítio Pedra do Cantagalo I com os pigmentos das pinturas rupestres do mesmo sítio; por fim, (v) prospectar jazidas de pigmentos minerais nas imediações do sítio e, caso existam, analisar a composição químico-mineralógica e magnética dos mesmos, para compará-los com os ocres coletados na superfície e em estratigrafia do sítio Pedra do Cantagalo I.

\section{OCRES}

Ocres são os pigmentos minerais mais comumente encontrados em sítios arqueológicos pré-históricos (MORTIMORE et al., 2004), tanto em superfície quanto em escavações. São vestígios menos numerosos do que outros materiais, como restos cerâmicos e líticos, mas que se destacam pela coloração que apresentam. Conforme mencionam Mortimore e colaboradores (2004), o termo ocre é utilizado de forma genérica para toda matéria colorida, desde tons do 
amarelo até o púrpura, cujas espécies responsáveis pela cor são óxidos de ferro.

Segundo argumentos dos autores citados, a cor desses materiais arqueológicos é influenciada por três fatores: (i) o tipo de óxido de ferro constituinte, pois os ocres vermelhos contêm hematita, enquanto os amarelos apresentam goethita; (ii) a composição dos ocres pode conter outros minerais, como argila ou diferentes óxidos metálicos e (iii) a distribuição de tamanho de partículas no material.

Segundo Popelka-Filcoff et al. (2007), o ocre pode se diversificar amplamente em relação ao seu teor mineralógico, podendo tanto ser composto por um óxido de ferro puro, quanto por misturas de óxidos de ferro com outros minerais. Esses pesquisadores expõem que, de modo geral, pode-se considerar o ocre como constituído por duas formas simples de óxido de ferro $\left(\mathrm{Fe}_{2} \mathrm{O}_{3}\right.$ e $\left.\mathrm{FeO}\right)$ misturados com argila, silicatos e outros minerais, variando da tonalidade púrpura profundo ao amarelo pálido, sendo que a coloração mais típica é um vermelho sangue. Os ocres vermelhos contêm cerca de $70 \%$ de ferro, principalmente hematita, e os amarelos podem variar a concentração de hidróxido, mais comumente com uma proporção em ferro de aproximadamente $63 \%$, contendo goethita ou limonita. Popelka-Filcoff et al. (2007) mencionam ainda que Robertson (1976) define ocre como sendo óxidos e hidróxidos ferruginosos, pobres em manganês, que são espacialmente e geneticamente associados a minerais de enxofre.

$\mathrm{Na}$ arqueologia, a palavra ocre é empregada para referenciar as substâncias de tonalidades diferentes, variando do vermelho sangue ao amarelo, em decorrência 
do tipo e quantidade de óxido ou hidróxido de ferro na constituição da matriz e da distribuição de tamanho de suas partículas (MOYO et al., 2016). Os principais óxidos de ferro são goethita, limonita, hematita, magnetita, maghemita e lepidocrocita podendo ser encontrados em diversas matrizes misturados com minerais brancos, tais como carbonato de cálcio, caulinita, quartzo, gipsita e talco (MOYO et al., 2016).

Trabalhos realizados no sítio arqueológico Dalmeri, localizado na cidade de Treno, na Itália, utilizaram o termo ocre para designar não apenas os pigmentos de tonalidade vermelha, compostos por hematita nas amostras analisadas, mas também os pigmentos brancos, compostos, por exemplo, por calcita, dolomita, entre outros (GIALANELLA et al., 2011).

Na geologia econômica, na mineração e na pintura são chamados ocres, os pigmentos da terra que exibem tonalidades em padrões de amarelo, vermelho e marrom. Já na terminologia do pigmento, o termo ocre é utilizado para se referir unicamente ao ocre amarelo. $\mathrm{O}$ óxido de manganês é o cromóforo que fornece às vezes a cor acastanhada aos pigmentos. Estas variedades de cores são encontradas em muitos depósitos de superfície e, consequentemente, são de relativamente fácil identificação. A sua composição mineralógica, o tamanho de suas partículas e a cristalinidade são elementos que podem indicar a sua origem. Os ocres encontrados na França são compostos por argila rica em goethita e em menor proporção por caulinita e ilita, enquanto os da Itália, da região da Toscana, contêm 
gesso e, às vezes, argilas expansivas, que aumentam de volume quando molhadas. Por outro lado, em áreas vulcânicas, onde comumente tem-se elevada atividade de enxofre, sulfatos de ferro podem ser encontrado e esses pigmentos são também denotados ocres (HRADIL et al., 2003).

Para Jácome (2006), as terras coloridas são pigmentos minerais utilizados pelas populações pré-históricas e que ainda são usados por pintores ocidentais, entre as quais estão os ocres. A autora menciona ocre como sendo uma terra natural que contém sílica e argila na sua constituição, destacando que a coloração desse material é decorrente dos óxidos de ferro como componentes de uma mistura.

Pereira (2009) cita que o ocre de tonalidade amarela foi utilizado no período préhistórico, tratando-se de um óxido de ferro hidratado opaco, o qual pode variar sua coloração devido ao local de extração, já que é um pigmento de origem mineral encontrado na natureza.

A origem do termo ocre vem da palavra grega ochros, que significa amarelo, sendo a goethita, em mistura com sílica e argila, a espécie ferruginosa responsável pela sua coloração (BARNETT; MILLER; PEARCE, 2006). O ocre vermelho pode ser obtido pelo aquecimento do ocre amarelo, procedimento que promove a transformação de uma fase mineral em outra, via/ eliminação de água. As matérias-primas utilizadas como pigmentos pelos homens pré-históricos foram extraídas diretamente da terra, comumente como argilas, contendo minerais que podem ser amassados e moldados na forma desejada, para uso na pintura e no 
desenho. O procedimento de preparação dos pigmentos consistia da moagem da matéria-prima, para se obter um pó, o qual era posto em um meio (extensor ou aglutinante), para produzir uma tinta que tivesse a aderência adequada, para fixála em uma superfície (BARNETT; MILLER; PEARCE, 2006).

Elias et al. (2006) mencionam que os ocres contêm quantidades variáveis de óxido de ferro em coordenação octaédrica, nomeadamente hematita e/ou goethita, e de pigmentos brancos (aluminossilicatos como caulinita ou ilita, quartzo e compostos de cálcio como calcita, anidrita, gipsita ou dolomita).

Na mesma linha de raciocínio, Moyo et al. (2016) e Popelka-Filcoff et al. (2008) colocam que a caracterização geoquímica dos ocres pode ser obtida pela determinação de sua matriz, do cromóforo, e da composição elementar. Relatam ainda que em casos de estudos de proveniência envolvendo ocres, a investigação dos elementos-traço, que participam de sua constituição e que consistem na chamada assinatura química, é de primordial importância para a diferenciação desses materiais. Moyo et al. (2016) mencionam também que a assinatura química dos óxidos de ferro, ao contrário do que ocorre com a composição mineral bruta, não é modificada pelas intempéries, nem tampouco pelo procedimento de preparação ao qual o ocre possa ter sido submetido na pré-história, pela localização geográfica da amostra e nem pelo processamento para análise. 
Nicolau (2016) explica que se deve primeiramente diferenciar o ocre natural do arqueológico, pois eles são diferenciados pelo fato de o ocre natural ser encontrado com abundância na natureza, enquanto o arqueológico é aquele que sofreu modificações antrópicas, com a finalidade de utilização em algum tipo de atividade humana, e que somente é encontrado em sítios arqueológicos. Nicolau (2016) menciona ainda que, para alguns arqueólogos, ocre é todo material contendo óxidos de ferro, com poder de pigmentação, tendo, ou não, argilominerais em sua composição. De forma mais rigorosa, Nicolau (2016) refere que para o material de pigmentação ser considerado ocre ele deve conter traços de argila ou areia, com maior ou menor quantidade de sílica, que compactam o mineral principal: hematita ou goethita. Em outras palavras, este autor menciona que o ocre é composto de óxido, ou hidróxido, de ferro compactado por argilas e/ou areias, embora também seja possível encontrar outros elementos compactados, como matéria orgânica, quartzo e dióxido de manganês.

\section{A utilização do ocre}

O ocre foi utilizado principalmente como pigmento para pintar algum tipo de material, mas também foi utilizado para outras finalidades, seja de caráter simbólico, uso funcional ou artístico. As evidências são os contextos arqueológicos distintos nos quais esse vestígio arqueológico é encontrado pelos pesquisadores. 
Couraud (1983) menciona que, na maioria das vezes, os colorantes (se referindo aos ocres) estão associados à função artística, porém as marcas de uso encontradas nos vestígios arqueológicos possibilitam reuni-los em dois conjuntos que se subdividem em quatro grandes funções: (i) técnicas artísticas, (ii) doméstica, (iii) mortuária, e (iv) suporte artístico.

Acredita-se que os ocres começaram a ser utilizados no fim do Paleolítico Médio e do musteriense, porém não foram encontrados vestígios arqueológicos desses materiais associados ao homem de Neandertal; as descobertas mais antigas são todas do Paleolítico Superior, entre Aurignacense e Magdalenense (GUERRERO I SALA; CASTANY I LLUSSA, 1991). Segundo esses pesquisadores, os ocres de tonalidade vermelha eram obtidos pela queima do ocre amarelo, feita pelo homem pré-histórico em fogueiras. Ainda de acordo com esses autores, no processo de preparação do material pigmentante, o ocre era amassado e moldado em bolas, que poderiam ser transportadas sem esforço e utilizadas em enxovais funerários; é importante registrar também o uso comum desse material na forma de pó, quer para preparar as terras da cova ou tumba em que o indivíduo era sepultado, ou como um manto sobre todo o corpo ou parte do falecido, ou era usado para pintar diretamente o crânio ou o esqueleto. Guerrero i Sala e Castany i Llussa (1991) mencionam que a pesquisa nos campos da Paleoetnologia e da Antropologia Cultural mostra por meios de seus estudos que o ocre pode ter sido empregado na maquiagem decorativa e na estética, como pintura corporal dos guerreiros, aplicado como inseticida sobre a pele; quando calcinado no fogo o ocre libera um 
aroma intenso das propriedades inseticidas e purificantes; os pesquisadores mencionados relatam também que os indígenas de tribos brasileiras usam o ocre como um tipo de adstringente, fortificante, cauterizante e antisséptico. De forma geral, o ocre é empregado para tingir peles e impermeabilizar a madeira. Os autores referem ainda que o ocre utilizado em rituais funerários atrasa a putrefação do corpo e serve para protegê-lo.

Padilla et al. (2012) mencionam que no sudeste da Península Ibérica foram evidenciados onze sítios arqueológicos com vestígios de esqueletos pigmentados com uma substância de coloração vermelha, em sepultamentos argáricos do período da Idade do Bronze. Dentre eles, destacam-se os sepultamentos encontrados em dois sítios arqueológicos de Alicante e em um de Múrcia, pela presença de ocre e cinábrio nos ossos humanos. Os sítios investigados na região de Alicante foram Illeta dels Banyets e Tabayá, e em Múrcia foi um assentamento localizado embaixo da área urbana de Lorca, especificamente a Calle Los Tintes e o Convento de las Madre Mercedarias. O ocre e o cinábrio foram encontrados mais frequentemente nos sepultamentos femininos, possivelmente mostrando a importância da mulher na cultura argárica. Porém, Padilla et al. (2012) não descartaram a possibilidade da utilização destes compostos para tingir os tecidos encontrados nos sepultamentos, além de sugerirem que tais materiais podem ter sido utilizados para fins de maquiagem facial ou corporal, dada a quantidade de esqueletos femininos evidenciados com pigmentos, em detrimento da pouca quantidade de esqueletos masculinos que passaram pelo mesmo processo. 
Wadley, Williamson e Lombard (2004) mencionam que o ocre, além de ser utilizado nas práticas simbólicas, também foi utilizado para outras finalidades, como uma substância de ação antibacteriana, assim como no processo de curtume, pois é favorável para impedir o processo de deterioração do couro. Os pesquisadores supracitados relatam os experimentos realizados por Audouin e Plisson (1982) os quais verificaram que os ocres avermelhados são mais efetivos no processo de conservação do couro, do que os ocres amarelos. Wadley, Williamson e Lombard (2004) relatam ainda o possível uso do ocre, misturado a resinas de plantas e amido, como uma espécie de cola para prender ferramentas líticas (pontas retocadas, raspadores, uma variedade de outros tipos de ferramentas retocadas e lascas não retocadas) ao suporte.

Barnett, Miller e Pearce (2006) relatam que os europeus, ao se depararem com os nativos da América do Norte, os chamaram de índios vermelhos, em decorrência deles utilizarem o corpo coberto por ocre dessa tonalidade, mencionando que o pigmento era utilizado com diversas funções, entre as quais para a proteção do corpo contra o frio durante o inverno e contra insetos no período do verão.

Forshaw (2009) relata que, no Egito, o ocre foi utilizado com outra função, conforme consta nos papiros médicos, particularmente no Papyrus Ebers 739, que cita uma receita de um remédio usado para consolidar os dentes, no qual o ocre era misturado com a farinha de sementes de emmer e mel, formando uma massa para ser aplicada no dente. O trigo de emmer parece ter sido utilizado de forma 
não seletivo, enquanto os ocres foram escolhidos porque são óxidos de ferro que têm propriedades adstringentes e antissépticas. O mel é um excelente agente aglutinante e, devido à sua hipertonicidade, mata microorganismos retirando a água por osmose (FORSHAW, 2009).

\section{Ocres e arqueometria}

Os ocres, assim como outros vestígios arqueológicos deixados pelos homens préhistóricos, são coletados pelos arqueólogos para serem analisados em laboratório, pois cada cultura material tem a sua especificidade, que, muitas vezes, não é detectada apenas por inspeção visual, pelo pesquisador; são necessários exames físicos e análises arqueométricas mais detalhados. Dependendo da complexidade do material, um conjunto intercomplementar de técnicas químico-analíticas é requerido. O campo científico interdisciplinar do conhecimento humano que utiliza técnicas de exames e de análises das ciências naturais, sobretudo da Química e da Física, para investigar materiais arqueológicos é a arqueometria (SCOTT; MEYERS, 1992; WAGNER; KYEK, 2004). O ponto principal desse tipo de abordagem reside na escolha correta das técnicas analíticas mais apropriadas, que se mostrem capazes de responder aos anseios do pesquisador.

Tendo em vista que a arqueometria abarca a investigação de diferentes tipos de materiais arqueológicos, neste trabalho, em especial, o foco está direcionado aos ocres vermelhos e amarelos, pela problemática que envolve a ocorrência, ou não, 
de preparação desses materiais pictóricos para a utilização em tintas de pinturas rupestres.

Cabral (1996) relata que em 1902 surgem os primeiros registros da aplicação de técnicas físico-químicas na investigação, realizada por Moissan (1902, 1903), de materiais picturais em pinturas pré-históricas das grutas de Font-de-Gaume e de La Mouthe. Cabral (1996) menciona ainda que na gruta de Altamira (Espanha) as análises físico-químicas dos materiais pictóricos das inscrições rupestres começaram somente a partir de 1977, apontando que os pigmentos vermelhos são constituídos essencialmente por hematita; os negros continham carvão vegetal, carvão animal (pó de ossos, chifres ou dentes queimados) ou óxidos de manganês; os castanhos e amarelos igualmente eram constituídos por hematita juntamente com goethita, em proporções variadas com o teor de goethita aumentando no sentido das tonalidades mais amareladas; o branco era resultante de uma mistura de argila micácea e quartzo; os cinzentos continham uma mescla semelhante à encontrada para o pigmento branco, com a característica de que a mica é uma ilita com relativamente alta cristalinidade. Esse mesmo pesquisador relata que os pigmentos vermelhos e negros continham adicionalmente quartzo e micas, eventualmente contendo ainda um material de origem orgânica, o âmbar, provavelmente acrescentado como um aglutinante. Conforme Cabral (1996), estudos semelhantes para as pinturas da gruta de Lascaux (França) foram iniciados apenas em 1979, utilizando amostras provenientes de escavações realizadas entre 1952 e 1963. 
Os resultados experimentais apontaram que os pigmentos vermelhos consistem de hematita, os negros são essencialmente constituídos por óxidos de manganês e menos frequentemente por carvão vegetal e os amarelos contêm goethita. Esse mesmo pesquisador ressalta que todos os componentes mencionados encontramse associados a determinados minerais, sobretudo quartzo, mas também calcita e argilominerais.

A partir dessas primeiras caracterizações de pigmentos de pinturas rupestres por técnicas físico-químicas, abriu-se uma janela para que mais pesquisadores pudessem galgar os mesmos caminhos pioneiramente investigativos, ampliando os mesmos procedimentos metodológicos para outros tipos de materiais arqueológicos, entre os quais os ocres. $\mathrm{O}$ avanço das tecnologias já existentes e o desenvolvimento de novas ferramentas analíticas possibilitaram ter-se um conhecimento mais aprofundado das camadas de tintas pré-históricas sobre os suportes rochosos e, consequentemente, dos pigmentos minerais empregados naquelas tintas, configurando-se a arqueometria como uma poderosa e indispensável estratégia experimental para investigar esses vestígios de atividade humana antiga.

No Nordeste do Brasil, no que diz respeito à análise de pigmentos minerais, envolvendo a arqueometria, os trabalhos são ainda restritos, porém algumas referências podem ser elencadas. O trabalho pioneiro mais abrangente sobre a composição químico-mineralógica de pigmentos de pinturas rupestres brasileiras 
foi efetuado por Lage (1990), na investigação de material pictórico oriundo de sítios de arte rupestre do sudeste do Piauí. Ao estudar as pinturas da Serra da Capivara, Lage $(1990,1996,1998,2007)$ verificou que os pigmentos utilizados na realização dos grafismos tinham a seguinte composição: os vermelhos continham hematita; os amarelos continham goethita; os cinzas consistiam de uma mistura de hematita com caulinita; os brancos podiam conter gipsita ou caulinita; e os pretos provinham de carvão de fonte vegetal ou de ossos queimados. Os exames e as análises físico-químicas por fluorescência de raios $\mathrm{X}(\mathrm{FRX})$ e difração de raios $\mathrm{X}$ (DRX) também mostraram que os ocres coletados em estratigrafia dos sítios arqueológicos ou provenientes de jazidas do entorno, igualmente investigados por Lage (1996), continham cristais de quartzo maiores do que os dos pigmentos utilizados nas tintas das pinturas rupestres. Os pigmentos minerais coletados em estratigrafia apresentaram similaridade de composição química elementar com os das jazidas. A interpretação final de Lage foi a de que os pigmentos minerais coletados das jazidas devem ter passado por um processo mecânico de preparação, que consistia na moagem e na filtração para eliminar os cristais de quartzo de maior tamanho, resultando em um material final mais fino e com os pigmentos mais concentrados.

Ramos (1995) efetuou o estudo arqueométrico dos pigmentos do sítio Pedra do Alexandre, localizado no Sertão do Seridó, no/Rio Grande do Norte. A pesquisadora determinou, a partir de testes micro-químicos e físicos, além de análises por DRX e FRX, que os pigmentos das pinturas rupestres são 
constituídos por óxido de ferro (porém sem mencionar qual é o óxido de ferro); verificou também que o material pictórico foi preparado, pois houve um cuidado na pulverização do óxido de ferro, que apresenta grãos de quartzo de pequena dimensão. Além dos pigmentos usados nas pinturas rupestres, Ramos investigou ainda amostras de pigmentos minerais coletados em estratigrafia (inclusive encontrados dentro de fogueiras), pigmentos minerais de tintas que cobriam esqueletos pintados com ocre (ou seja, utilizados em rituais funerários) e pigmentos retirados diretamente das jazidas próximas ao sítio. Os exames físicos feitos nos pigmentos coletados em estratigrafia permitiram identificar marcas de uso e apontaram cristais vermelhos e amarelos (como os que foram identificados tanto nos pigmentos empregados nos grafismos rupestres quanto naqueles oriundos das jazidas do entorno), ao passo que os exames dos ocres queimados e dos pigmentos utilizados para pintar os esqueletos revelaram apenas cristais vermelhos.

Marcélia Marques e Conceição Lage (2008) relatam a utilização de exames e análises por FRX, para investigar as pinturas rupestres da região do Sertão Central do Ceará, Nordeste do Brasil, com o intuito de verificar as semelhanças e diferenças entre os pigmentos das pinturas rupestres dos sítios daquela região, comparativamente aos das pinturas do sudeste do Piauí e do Seridó, Rio Grande do Norte. Os resultados obtidos dessa pesquisa foram correlacionados com os obtidos para os sítios da região de São Raimundo Nonato, Piauí (LAGE, 1990), e com os da região do Seridó, Rio Grande do Norte, obtidos por Ramos (1995). Na 
correlação efetuada, as pesquisadoras mencionam que a espessura da camada pictórica nas pinturas do Ceará é fina e descontínua e, ainda, que não apresenta cristais de quartzo, indicando, segundo elas, que o pigmento deve ter sido preparado. A análise por FRX revelou que os pigmentos vermelhos são constituídos por argilosos à base de óxido de ferro (ocre) e mostrou ainda traços de elementos químicos como magnésio, alumínio e titânio, em quantidades variadas. Porém, o pigmento alaranjado apresentou uma quantidade maior de cálcio, em relação à de ferro.

Marques e Lage (2008) ainda relatam com detalhes, na mesma publicação, a rotina de preparação dos pigmentos por índias Tremembé atuais. Resumidamente, as autoras mencionadas descrevem o processo de preparação dos pigmentos, informando que, após serem coletados, eles são depositados separadamente, conforme cada cor específica, em recipientes, nos quais água é adicionada e em seguida o material é repetidamente esfregado com as próprias mãos. Após a decantação, quando o sobrenadante é descartado, mais água é acrescentada, e repete-se o processo. Em uma etapa seguinte, o material é coado com um tecido fino e ralo. Os minerais de pequena granulometria passam pelo tecido e são denominados "goma", pelas índias, resultando semelhante a uma pasta fina. Finalmente, o material obtido é submetido a uma última fase de decantação, e a pasta final pode ser acondicionada em potes e usada em seguida. A última retirada de sobrenadante se faz diretamente, derramando a água no chão. Esse é o processo de preparo dos pigmentos de ocre vermelho e ocre amarelo. O pigmento branco é 
obtido diretamente do caulim, simplesmente misturado com água, pois não precisa ser decantado, devido ao fato de a granulometria já ser suficientemente fina. O pigmento azul é obtido pelo acréscimo de carvão vegetal, que é peneirado em um tecido ralo e então misturado ao pigmento branco resultante do caulim.

Cavalcante et al. (2011) investigaram amostras de ocres utilizados em rituais funerários humanos do sítio Toca do Enoque, localizado na Serra das Andorinhas, Parque Nacional Serra das Confusões, no Piauí. Os pigmentos foram analisados por espectroscopia Mössbauer do ${ }^{57} \mathrm{Fe}$ em geometria de transmissão, considerada como uma ferramenta importante para a caracterização químico-mineralógica desse tipo de material, uma vez que ocres avermelhados e amarelados contêm espécies ferruginosas em sua constituição. Complementarmente os autores também utilizaram DRX e espectroscopia no infravermelho (IV). Os dados obtidos revelaram que os pigmentos minerais eram constituídos predominantemente por hematita (ocre vermelho) ou goethita (ocre amarelo), em ambos os casos misturados com quartzo, e que uma fração da hematita apresentase bem cristalizada e com tamanhos de partículas maiores.

Em seu doutorado em Ciências - Química, Cavalcante (2012) analisou pinturas rupestres pré-históricas, pigmentos minerais e eflorescências salinas de diversos sítios arqueológicos do Brasil (Piauí, Bahia e Ceará) e da Argentina (Parque Nacional Perito Moreno), com o intuito de efetuar a caracterização arqueométrica desses materiais, visando também contribuir para a conservação dos registros 
rupestres. Identificou, usando várias técnicas analíticas (espectroscopia Mössbauer do ${ }^{57} \mathrm{Fe}$ nas geometrias de elétrons de conversão e de transmissão de raios gama; DRX em incidência rasante; espectroscopia de energia dispersiva; microscopia eletrônica de varredura; DRX; FRX e IV) que as pinturas vermelhas foram preparadas com materiais ricos em hematita; as pinturas amarelas foram feitas com goethita; as pretas continham carbono (provavelmente oriundo de carvão vegetal); a pintura cinza foi preparada com uma mistura de carbono e aluminossilicatos. De modo geral, as análises apontaram que as partículas dos óxidos e oxidróxidos de ferro se apresentam como sendo de pequeno tamanho médio de partículas, com elevada substituição isomórfica de diferentes cátions por ferro e baixa cristalinidade. Cavalcante concluiu que os pigmentos minerais vermelhos continham uma mistura de hematita, quartzo, caulinita, ilita e $\mathrm{KAl}_{3}\left(\mathrm{SO}_{4}\right)_{2}(\mathrm{OH})_{6} ;$ o pigmento mineral amarelo era constituído por goethita, misturada com quartzo e caulinita; o branco era constituído principalmente por ilita e quartzo.

Esses trabalhos mostram a importância da arqueometria, ferramenta indispensável à caracterização químico-mineralógica de vestígios arqueológicos, revelando dados que permitem ao pesquisador responder diversos questionamentos sobre os pigmentos utilizados pelos grupos humanos mais antigos, ditos pré-históricos ou, no caso brasileiro, pré-coloniais, assim como sobre a técnica de preparo usada pelos autores das pinturas rupestres, entre outras questões que possam surgir no 
decorrer do processo investigativo ou até mesmo dos resultados obtidos a partir dos exames e das análises físico-químicas.

\section{O SÍTIO PEDRA DO CANTAGALO I}

Encravado no baixo vale do riacho Corrente, no povoado Jardim, área rural do município de Piripiri, estado do Piauí, encontra-se o sítio arqueológico Pedra do Cantagalo I, um grande abrigo sob-rocha, modelado por erosão alveolar em arenito da Formação Cabeças, Membro Oeiras, localizado nas coordenadas geográficas $4^{\circ} 25^{\prime} 7,7^{\prime \prime}$ de latitude sul e $41^{\circ} 40^{\prime} 20,2^{\prime}$ ' de longitude oeste, a cerca de 232 metros de altitude, em relação ao nível médio do mar (CAVALCANTE et al., 2014). Mais de 1950 pinturas rupestres decoram 80 metros e 30 centímetros de comprimento de paredes, reentrâncias e saliências rochosas da área abrigada desse sítio arqueológico, e, em sua maioria, foram pintadas em diferentes tonalidades de vermelho, ocorrendo, em menor proporção, inscrições nas cores preta, amarela, rosa, branca, alaranjada, púrpura e cinza (CAVALCANTE; RODRIGUES, 2010). Gravuras rupestres igualmente distribuem-se nos painéis pictóricos, algumas das quais encontram-se pintadas; diversos pilões são facilmente identificados no piso rochoso do abrigo, e provavelmente devem ter sido utilizados para macerar algum tipo de material orgânico ou mineral (CAVALCANTE; RODRIGUES, 2010). Figuras abstratas, antropomorfos, zoomorfos/propulsores de dardos e carimbos de mãos humanas estão entre as inscrições mais frequentemente representadas neste sítio arqueológico, no qual observam-se muitas recorrências e sobreposições dos motivos pintados (CAVALCANTE; RODRIGUES, 2010). 
Além das inscrições rupestres existentes nas paredes rochosas do sítio Pedra do Cantagalo I, os sedimentos superficiais da área abrigada continham diversos vestígios de cultura material, tais como líticos lascados e polidos, fragmentos cerâmicos e pigmentos minerais (CAVALCANTE; RODRIGUES, 2010).

Em agosto de 2014, foi iniciada a escavação desse sítio pré-colonial, inicialmente pela realização de duas sondagens, cujo interesse foi a busca de vestígios de atividade humana antiga em subsuperfície, além da coleta de paleossedimentos, para posteriores análises químico-mineralógicas. O sítio Pedra do Cantagalo I foi sondado pelo fato de a área abrigada conter um acúmulo de sedimento propício para escavação e pelas evidências de cultura material coletada da superfície dos sedimentos próximos às paredes decoradas com as inscrições rupestres. Por essa razão, duas sondagens foram, então, abertas, em agosto de 2014. A primeira, com dimensões de $3 \mathrm{~m}$ x $2 \mathrm{~m}$ e a segunda, com dimensões consideravelmente menores, de $1 \mathrm{mx} 1 \mathrm{~m}$. Dessas sondagens foram coletados 21 fragmentos cerâmicos, 18 amostras de ocres vermelhos, 18 amostras de carvão, 8 líticos, 8 fragmentos de osso, 6 amostras de ocres amarelos, 1 fragmento de material orgânico, 1 fragmento de parede rochosa com resíduos de tinta, além de 25 amostras de sedimentos arqueológicos.

Três estruturas de combustão foram evidenciadas, respectivamente, nas quadrículas A2, B2 e C2, da sondagem 1, das quais as amostras de carvões foram coletadas. Uma amostra de carvão (PCI.2014.104), da decapagem 5 da quadrícula 
$\mathrm{A} 2$, da base da estrutura de combustão 1 , foi datada pelo método ${ }^{14} \mathrm{C} \mathrm{AMS}$, no Beta Analytic (Beta - 420913), revelando uma idade de $1180 \pm 30$ anos antes do presente (BP; resultado calibrado, com 95\% de probabilidade, de 1070 a 960 anos BP) (CAVALCANTE et al., 2017).

Dada a ocorrência de ocres vermelhos e amarelos, tanto na superfície quanto na subsuperfície, do sítio Pedra do Cantagalo I, a prospecção de fontes de matériaprima mineral nas proximidades do abrigo rochoso tornou-se um aspecto importante, tanto para correlações arqueológicas assim como para arqueométricas. Nas expedições de campo realizadas, cinco jazidas desses materiais foram encontradas e investigadas neste trabalho (SILVA; CAVALCANTE; FABRIS, 2017).

\section{PROCEDIMENTO EXPERIMENTAL}

\section{As amostras analisadas}

Os ocres analisados neste trabalho foram coletados in situ, diretamente da superfície dos sedimentos passíveis de escavação do sítio Pedra do Cantagalo I, em expedições realizadas em 2010 e 2012. No entanto, a maioria das amostras investigadas foi recolhida na escavação, já mencionada, empreendida em agosto de 2014. Ao total quinze amostras representativas dos ocres foram analisadas. Os critérios adotados para a seleção das amostras representativas foram i) diferentes padrões cromáticos dos ocres, ii) quantidade adequada de material disponível para 
as medidas experimentais e iii) ocorrência ou não de caráter magnético dos ocres mensurado por ensaio com um pequeno ímã permanente de mão.

Os pigmentos minerais das jazidas identificadas no entorno do sítio Pedra do Cantagalo I também foram investigadas neste trabalho. Nove amostras representativas, de um universo de vinte e uma, dos pigmentos minerais coletados, em março e junho de 2015, diretamente das jazidas identificadas nas imediações do abrigo rochoso, foram analisadas. Os critérios adotados para a seleção das amostras representativas dos pigmentos minerais das jazidas foram i) diferentes padrões cromáticos dos pigmentos e ii) ocorrência ou não de caráter magnético desses materiais mensurado por ensaio com ímã permanente de mão. $\mathrm{O}$ critério quantidade adequada de material disponível para as medidas experimentais não foi necessário, já que a abundância dos pigmentos nas jazidas possibilitou a coleta de quantidade considerável de material, mais do que o mínimo requerido para as análises arqueométricas.

\section{As análises arqueométricas}

No Laboratório de Arqueometria, do Curso de Graduação em Arqueologia da Universidade Federal do Piauí, as amostras de ocre e de pigmentos minerais das jazidas foram pulverizadas e analisadas com um espectrômetro Mössbauer miniaturizado MIMOS II e as amostras em temperatura ambiente. Uma sondagem preliminar do caráter magnético dos materiais investigados foi efetuada usando ímã permanente de mão. Na Universidade Federal de Minas Gerais (UFMG), em 
Belo Horizonte, Minas Gerais, foi realizada a análise de algumas amostras por espectroscopia de absorção na região do infravermelho. No Centro de Desenvolvimento da Tecnologia Nuclear (CDTN), em Belo Horizonte, foram efetuadas medidas experimentais por FRX, DRX do pó, e espectroscopia Mössbauer do ${ }^{57} \mathrm{Fe}$ em geometria de transmissão de raios gama com as amostras em baixa temperaturas. Na Universidade Federal dos Vales do Jequitinhonha e Mucuri (UFVJM), em Diamantina, Minas Gerais, foram feitas análises por DRX do pó e determinação de carbono por análise elementar por $\mathrm{CHN}$; condições experimentais em Cavalcante et al. (2017) e em Silva, Cavalcante e Fabris (2017).

\section{Correlação de dados}

A confrontação dos dados aqui obtidos de composição químico-mineralógica dos ocres vermelhos e amarelos do sítio Pedra do Cantagalo I com os dados correspondentes para as camadas de tintas das pinturas rupestres existentes nas superfícies areníticas decoradas, deste sítio pré-histórico, foi realizada utilizandose os resultados, para os filmes pictóricos, já previamente obtidos, por Cavalcante (2012), Cavalcante e Alves (2014) e Silva (2015). O objetivo foi buscar indícios que permitissem apontar o uso desses ocres na elaboração das pinturas rupestres mencionadas.

Por outro lado, a confrontação dos dados obtidos de composição químicomineralógica dos ocres coletados em superfície e nas sondagens e dos pigmentos minerais das jazidas do entorno do sítio Pedra do Cantagalo I foi útil para a 
investigação de indícios de preparação dos referidos ocres, a partir dos pigmentos das jazidas existentes no entorno do sítio.

\section{RESULTADOS E DISCUSSÃO}

Um ensaio com um pequeno ímã permanente de mão indicou que alguns ocres vermelhos têm material magnético entre seus constituintes e a pulverização dos ocres amarelos revelou que algumas amostras têm apenas a superfície amarela, mas que o núcleo é vermelho. Os resultados gerais obtidos deste trabalho foram aglomerados para cada um desses conjuntos de amostras: ocres vermelhos, ocres vermelhos magnéticos, ocres amarelos e ocres com superfície amarela e núcleo vermelho. Tendo em vista a ampla gama de dados obtidos das medidas experimentais, reporta-se aqui um breve resumo apenas sobre os resultados referentes aos ocres vermelhos e amarelos, além de resultados obtidos para amostras representativas dos pigmentos minerais, de cores correspondentes, das jazidas do entorno do sítio Pedra do Cantagalo I.

\section{Ocres vermelhos e amarelos}

Considerando duas amostras representativas dos ocres vermelhos e duas dos ocres amarelos, Cavalcante e colaboradores (2017) encontraram que os vermelhos contêm um teor de ferro, conforme determinado por FRX, expresso como $\mathrm{Fe}_{2} \mathrm{O}_{3}$, de $\sim 60$ a $\sim 68$ massa\% e que nos ocres amarelos a proporção correspondente é de 34 massa\%. Dos espectros Mössbauer obtidos para essas amostras de ocres vermelhos, hematita (fórmula ideal $\alpha \mathrm{Fe}_{2} \mathrm{O}_{3}$ ) ou uma mistura de hematita e goethita 
$(\alpha \mathrm{FeOOH})$, foram identificadas. Como esperado para amostras com essa complexidade, os espectros Mössbauer registrados em temperatura ambiente para os ocres amarelos mostraram perfis com linhas de ressonância muito alargadas, destacando-se um dupleto central atribuível a $\mathrm{Fe}^{3+}$, presumidamente devido a óxidos/oxidróxidos de ferro de pequeno tamanho de partículas e com relaxação superparamagnética. Os perfis Mössbauer observados em $25 \mathrm{~K}$ (Figura 1) para ambos os ocres permitiram confirmar essa suposição, já que os efeitos de relaxação superparamagnética foram praticamente suprimidos e as contribuições espectrais devidas à goethita puderam, assim, ser mais facilmente separadas. Os dados obtidos por DRX (Figura 1) para os ocres vermelhos confirmaram a ocorrência de hematita e goethita nesses materiais arqueológicos, além de mostrarem a presença de quartzo e ilita. Para os ocres amarelos, os resultados obtidos por DRX confirmaram a ocorrência de goethita, além de apontarem quartzo e rutilo.

\section{Pigmentos minerais de jazidas}

Sobre a caracterização químico-mineralógica dos pigmentos minerais das jazidas, especificamente dos vermelhos e dos amarelos, Silva, Cavalcante e Fabris (2017) reportaram que o teor de ferro, determinado por FRX, expresso na forma de $\mathrm{Fe}_{2} \mathrm{O}_{3}$, é de $\sim 19$ a $\sim 21$ massa\% nos vermelhos e de $\sim 12$ massa $\%$ no amarelo. Espectros Mössbauer (Figura 2) obtidos para esses materiais mostraram sextetos atribuíveis à hematita e dupletos de $\mathrm{Fe}^{3+}$ para os pigmentos vermelhos. Alguns campos magnéticos hiperfinos relativamente baixos para a hematita sugerem que 
frações desse óxido de ferro têm pequenos tamanhos de partículas. $\mathrm{O}$ espectro Mössbauer para o pigmento amarelo mostrou apenas dois dupletos de $\mathrm{Fe}^{3+}$, atribuíveis a espécies superparamagnéticas, muito provavelmente incluindo goethita, de pequenos tamanhos de partículas, ou a ferro paramagnético na estrutura cristalina de aluminossilicatos.
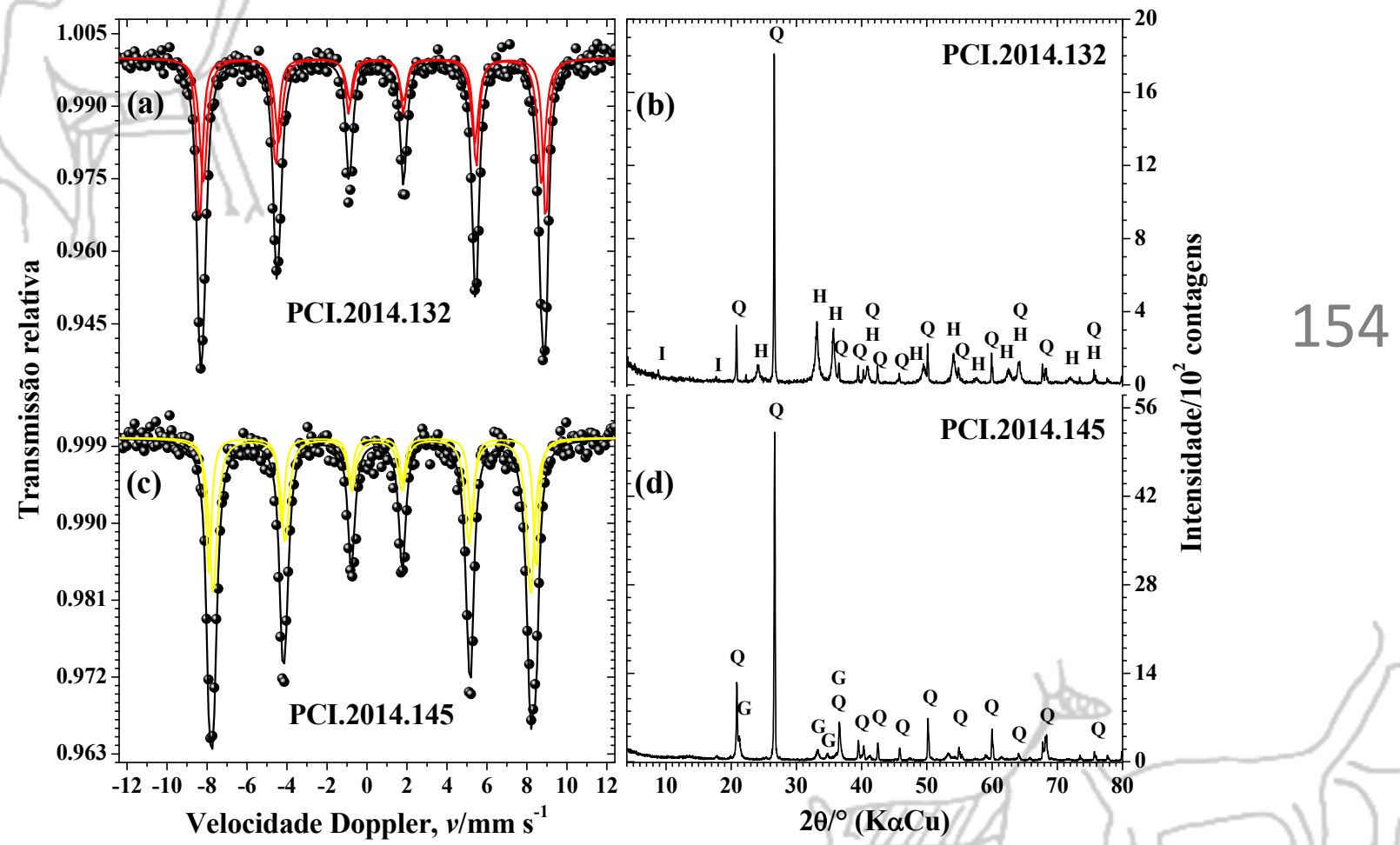

Figura 1: Espectros Mössbauer a $25 \mathrm{~K}$ (a e c) e padrões de DRX (b e d) para amostras representativas dos ocres vermelhos (PCI.2014.132) e dos amarelos (PCI.2014.145). $\mathrm{Q}=$ quartzo, $\mathrm{H}=$ hematita, $\mathrm{G}=$ goethita, $\mathrm{I}=$ ilita, $\mathrm{R}=$ rutilo. 
Os padrões de DRX desses pigmentos minerais (Figura 2) mostraram reflexões de Bragg características de quartzo e caulinita, para os vermelhos, e de quartzo, caulinita, ilita, albita e rutilo, para os amarelos.
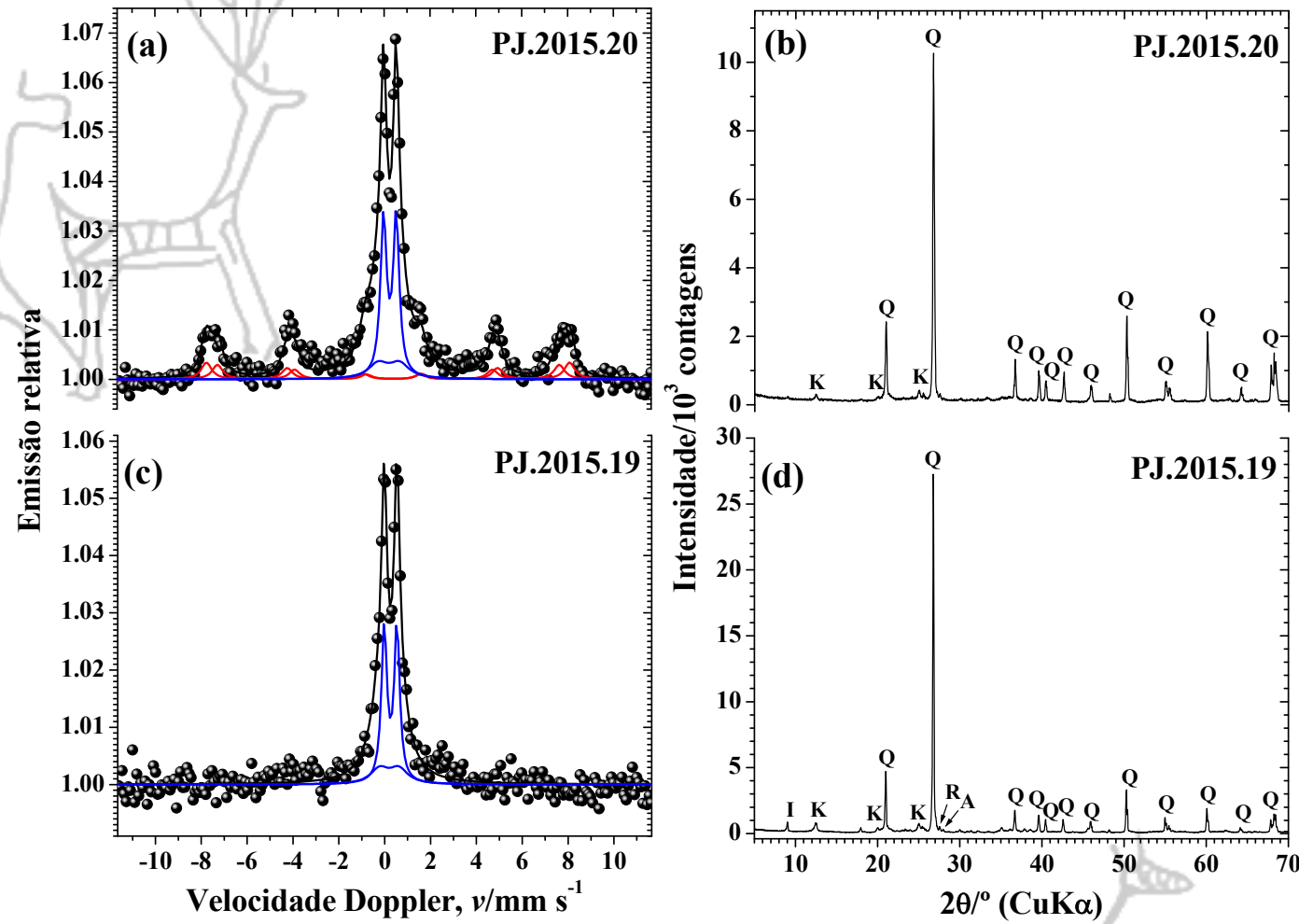

Figura 2: Espectros Mössbauer a $298 \mathrm{~K}$ (a e c) e padrões de DRX (b e d) para amostras representativas dos pigmentos minerais vermelhos (PJ.2015.20) e amarelos (PJ.2015.19) das jazidas do entorno do sítio Pedra do Cantagalo $\mathrm{I} . \mathrm{Q}=$ quartzo, $\mathrm{I}=$ ilita, $\mathrm{R}=$ rutilo, $\mathrm{K}=$ caulinita, $\mathrm{A}=$ albita.

\section{CONSIDERAÇÕES FINAIS}

O sítio Pedra do Cantagalo I é um patrimônio arqueológico de reconhecida importância para o conhecimento da arqueologia pré-histórica do centro-norte do 
Piauí e que, portanto, deve ser preservado, pela diversidade de vestígios de atividade humana nele encontrados. A cultural material evidenciada nesse sítio já proporcionou a realização de vários trabalhos acadêmicos e continua possibilitando novas investigações, que visam compreendê-lo como um todo, seja através da matéria-prima utilizada para confeccionar os artefatos líticos, os ocres encontrados em superfície ou em estratigrafia, as camadas de tintas das pinturas rupestres, os restos cerâmicos, ou seja pelos diferentes olhares que se podem lançar sobre as pinturas e gravuras rupestres, assim como pela avaliação da relação do sítio com o meio natural no qual está inserido.

Neste trabalho realizou-se a análise arqueométrica de ocres vermelhos e amarelos encontrados no sítio Pedra do Cantagalo I e de amostras de pigmentos minerais de jazidas existentes em seu entorno. Os dados Mössbauer obtidos para os ocres vermelhos e amarelos indicam que esses materiais contêm óxidos e oxidróxidos de ferro com diferentes tamanhos de partículas, alguns com tamanho relativamente grande e alta cristalinidade e outros com tamanho relativamente menor, com campos magnéticos hiperfinos relativamente mais baixos e linhas de ressonância mais alargadas, apontando para frações dessas espécies ferruginosas com diferentes graus de substituição isomórfica do ferro por outros cátions, na estrutura cristalina.

A ausência ou virtual baixo teor desses óxidos e oxidróxidos de ferro apontados por difratometria de raios $\mathrm{X}$ é um indício a mais de que essas espécies 
ferruginosas apresentam elevada substituição isomórfica do ferro por outros cátions, na estrutura cristalina, resultando, pois, em baixa cristalinidade.

Em síntese, os ocres vermelhos são constituídos predominantemente por hematita, ou por uma mistura de hematita com goethita ou ainda de hematita com maghemita; quartzo, muscovita, ilita e caulinita também foram encontrados. Os ocres amarelados contêm essencialmente goethita, quartzo e caulinita.

Propôs-se uma correlação dos dados de composição químico-mineralógica dos ocres aqui investigados com dados correspondentes obtidos previamente para as camadas de tintas das pinturas rupestres do sítio Pedra do Cantagalo I, a partir da qual foi possível apontar quatro amostras de ocres que podem ter sido utilizadas na confecção de quatro pinturas rupestres desse mesmo sítio arqueológico.

Tendo em vista a compatibilidade dos dados químico-mineralógicos obtidos para os ocres encontrados nos sedimentos superficiais e nas sondagens realizadas no abrigo Pedra do Cantagalo I e para os pigmentos minerais das jazidas existentes no entorno desse sítio arqueológico e considerando que tais ocres teriàm sido obtidos diretamente das fontes minerais próximas, buscou-se indícios de preparação dos pigmentos das jazidas (precursores), para a obtenção dos ocres eventualmente usados na confecção das pinturas rupestres deste abrigo préhistórico. Os resultados obtidos para os ocres vermelhos coletados dos sedimentos superficiais e das sondagens mostram evidências consideravelmente nítidas de que 
as fases ferruginosas, assim como os minerais contendo alumínio, foram enriquecidos no material final (ocre vermelho), aparentemente às expensas da eliminação de minerais silicatados, a partir do material retirado das jazidas. Os dados obtidos para os ocres amarelos também revelam evidências consideravelmente claras de enriquecimento das fases ferruginosas no material final (ocre amarelo), virtualmente às expensas de eliminação de minerais contendo alumínio e de fases ricas em enxofre e fósforo, a partir do material oriundo das jazidas.

A ocorrência de material magnético em algumas amostras de ocres vermelhos e a não detecção de espécies ferruginosas correspondentes nos pigmentos minerais das jazidas pressupõe o uso provável de aquecimento na preparação desses ocres, a partir dos precursores recolhidos das jazidas próximas ao sítio arqueológico.

Os resultados obtidos das medidas experimentais apontarem para a preparação dos ocres, a partir dos pigmentos minerais encontrados nas jazidas correspondentes do entorno do sítio Pedra do Cantagalo I, bem como a possível utilização de aquecimento como parte da tecnologia de preparação desses materiais pictóricos, é substancialmente coerente com os vestígios arqueológicos encontrados no abrigo pré-histórico, como dezenas de pilões no piso arenítico da área abrigada e de um moedor com resquícios de pigmentos amarelos e vermelhos, além de três estruturas de combustão evidenciadas em subsuperfície, no nível das quais ocres foram coletados. 


\section{REFERÊNCIAS BIBLIOGRÁFICAS}

AUDOUIN, F.; PLISSON, H. Les ochres et leurs témoins au Paléolithique em France: enquéte et expériences sur leur validité archéologique. Cahiers du Centre de Recherches Préhistoriques, n. 8, p. 33-80, 1982.

BARNETT, J. R.; MILLER, S.; PEARCE, E. Colour and art: a brief history of pigments. Optics \& Laser Technology, v. 38, n. 4-6, p. 445-453, 2006.

CABRAL, J. M. P. História breve dos pigmentos - da arte do homem pré-histórico. Química - Boletim da Sociedade Portuguesa de Química, n. 62, p. 11-18, 1996.

CAVALCANTE, L. C. D. Caracterização arqueométrica de pinturas rupestres préhistóricas, pigmentos minerais naturais e eflorescências salinas de sítios arqueológicos. Tese (Doutorado em Ciências - Química) - Universidade Federal de Minas Gerais, Belo Horizonte, 2012.

CAVAlCANTE, L. C. D.; ALVES, Y. R. V. Caracterização mineralógica de pinturas rupestres do sítio Pedra do Cantagalo I por espectroscopia Raman. Relatório Final de Iniciação Científica PIBIC/CNPq/UFPI 2013-2014. Teresina: CPES-PROPESQ-UFPI, 2014.

CAVALCANTE, L. C. D.; LUZ, M. F.; GUIDON, N.; FABRIS, J. D.; ARDISSON, J. D. Ochres from rituals of prehistoric human funerals at the Toca do Enoque site, Piauí, Brazil. Hyperfine Interactions, v. 203, n. 1-3, p. 39-45, 2011.

CAVAlCANTE, L. C. D.; RODRIGUES, A. A. Arte rupestre e problemas de conservação da Pedra do Cantagalo I. International Journal of South American Archaeology, n. 7, p. 15-21, 2010.

CAVAlCANTE, L. C. D.; RODRIGUES, A. A.; COSTA, E. N. L.; SILVA, H. K. S. B.; RODRIGUES, P. R. A.; OLIVEIRA, P. F.; ALVES, Y. R. V.; FABRIS, J. D. Pedra do Cantagalo I: uma síntese das pesquisas arqueológicas. Arqueología Iberoamericana, v. 23, p. 45-60, 2014.

CAVAlCANTE, L. C. D.; SILVA, H. K. S. B.; FABRIS, J. D.; ARDISSON, J. D. Red and yellow ochres from the archaeological site Pedra do Cantagalo I, in Piripiri, Piauí, Brazil. Hyperfine Interactions, v. 238, p. 22.1-7, 2017. 
COURAUD, C. Pour une étude méthodologique dês colorants préhistoriques. Bulletin de la Société préhistorique française, v. 80, n. 4, p. 104-110, 1983.

DESCARTES, R. Discurso do método. São Paulo: Martins Fortes, 2001.

ELIAS, M.; CHARTIER, C.; PRÉVOT, G.; GARAY, H.; VIGNAUD, C. The colour of ochres explained by their composition. Materials Science and Engineering B, v. 127, n. 1, p. $70-80,2006$.

FORSHAW, R. J. The practive of dentistry in ancient Egypt. British Dental Journal, v. 206, n. 9, p. 481-486, 2009.

GIALANELLA, S.; BELLI, R.; DALMERI, G.; LONARDELLI, I.; MATTARELLI, M.; MONTAGNA, M.; TONIUTTI, L. Artificial or natural origin of hematite-based red pigments in archaeological contexts: the case of Riparo Dalmeri (Treno, Italy). Archaeometry, v. 53, n. 5, p. 950-962, 2011.

GUERRERO I SALA, L.; CASTANY I LLUSSA, J. L'ocre vermell a la prehistòria, i l'us terapèutic de les argiles. Gimbernat: revista catalana d'història de la medicina i de la ciência, v. 15, p. 147-153, 1991.

HRADIL, D.; GRYGAR, T.; HRADILOVÁ, J.; BEZDICKA, P. Clay and iron oxide pigments in the history of painting. Applied Clay Science, v. 22, n. 5, p. 223-236, 2003. JÁCOME, C. P. Ayquatiá da Yapepó: estudo dos materiais utilizados na cerâmica pintada Tupiguarani de Minas Gerais. 2006. 151 f. Dissertação (Mestrado em Artes Visuais) Universidade Federal de Minas Gerais, Belo Horizonte, 2006.

LAGE, M. C. S. M. A conservação de sítios de arte rupestre. Revista do Patrimônio Histórico e Artístico Nacional, n. 33, p. 95-107, 2007.

LAGE, M. C. S. M. Análise química de pigmentos de arte rupestre do sudeste do Piauí. Revista de Geologia, v. 9, p. 83-96, 1996.

LAGE, M. C. S. M. Datações de pinturas rupestres da área do PARNA Serra da Capivara. Clio Arqueológica, n. 13, p. 203-213, 1998. 
LAGE, M. C. S. M. Etude archéométrique de l'art rupestre du sud-est Piauí-Brésil. 1990. 407 f. Tese (Doctorat Anthropologie, Ethnologie, Prehistorie) - Université de Paris I, Paris, 1990.

MARQUES, M.; LAGE, C. A preparação da tinta pré-histórica numa expectativa etnoarqueológica e a materialidade da tela rupestre. O Público e o Privado, n. 12, p. 83$102,2008$.

MORTIMORE, J. L.; MARSHALL, L. R.; ALMOND, M. J.; HOLlinS, P.; MATTHEWS, W. Analysis of red and yellow ochre samples from Clearwell Caves and Çatalhöyük by vibrational spectroscopy and other techniques. Spectrochimica Acta Part $A$, v. 60, n. 5, p. $1179-1188,2004$.

MOYO, S.; MPHUTHI, D.; CUKROWSKA, E.; HENSHILWOOD, C. S.; VAN NIEKERK, K.; CHIMUKA, L. Blombos Cave: Middle Stone Age ochre differentiation through FTIR, ICP OES, ED XRF and XRD. Quaternary International, v. 404, p. 20-29, 2016.

NICOLAU, A. C. Ocre, hematites y óxido de hierro: el problema terminológico. Espacio, Tiempo y Forma - Série I (Prehistoria y Arqueología), n. 9, p. 13-42, 2016.

PADILlA, J. A. L.; IBÁÑEZ, M. P. M.; ROSA, M. A.; MARTÍN, L. G.; GARCÍA, C. R.; MASCARÓS, S. M. Ocre y cinabrio em el registro funerario de El Argar. Trabajos de Prehistoria, v. 69, n.2, p. 273-292, 2012.

PEREIRA, R. M. N. Pigmentação de rochas. 2009. 117 f. Dissertação (Mestrado em Engenharia de Minas e Geo-Ambiente) - Universidade do Porto, Porto, 2009.

POPELKA-FILCOFF, R. S.; MIKSA, E. J.; ROBERTSON, J. D.; GLASCOCK, M. D.; WALLACE, H. Elemental analysis and characterization of ochre sources from Southern Arizona. Journal of Archaeological Science, v. 35, n. 3, p. 752-762, 2008.

POPELKA-FILCOFF, R. S.; ROBERTSON, J. D.; GLASCOCK, M. D.; DESCANTES, $\mathrm{CH}$. Trace element characterization of ochre from geological sources. Journal of Radioanalytical and Nuclear Chemistry, v. 272, n. 1, p. 17-27, 2007. 
RAMOS, A. C. P. T. O sítio pré-histórico rupestre Pedra do Alexandre em Carnaúba dos Dantas, $R N$ : estudo dos pigmentos. 1995. $107 \mathrm{f}$. Dissertação (Mestrado em História) Universidade Federal de Pernambuco, Recife, 1995.

ROBERTSON, A. H. F. Origins of ochres and umbers: evidence from Skouriotissa, Troodos Massif, Cyprus. Transactions of the Institute of Metallurgy, B, v. 85 p. 245-251, 1976.

SCOTT, D. A.; MEYERS, P. (Ed.). Archaeometry of pre-columbian sites and artifacts. Los Angeles: UCLA Institute of Archaeology, Getty Conservation Institute, 1992.

SILVA, H. K. S. B. Análise de pinturas rupestres da pedra do Cantagalo I com um espectrômetro Mössbauer miniaturizado MIMOS II. Trabalho de Conclusão de Curso (Graduação em Arqueologia e Arte Rupestre) - Universidade Federal do Piauí, Teresina, 2015.

SILVA, H. K. S. B.; CAVALCANTE, L. C. D.; FABRIS, J. D. Características químico-mineralógicas de fontes de pigmentos minerais em depósitos naturais do entorno do sítio arqueológico Pedra do Cantagalo I, em Piripiri, Piauí, Brasil. Arqueología Iberoamericana, v. 36, p. 36-42, 2017.

WADLEY, L.; WILLIAMSON, B.; LOMBARD, M. Ochre in hafting in Middle Stone Age souther Africa: a practical role. Antiquity, v. 78, n. 301, p. 661-675, 2004.

WAGNER, F. E.; KYEK, A. Mössbauer spectroscopy in archaeology: introduction and experimental considerations. Hyperfine Interactions, v. 154, n. 14, p. 5-33, 2004. 